\title{
Effect of Removal of Woody Biomass after Clearcutting and Intercropping Switchgrass (Panicum virgatum) with Loblolly Pine (Pinus taeda) on Rodent Diversity and Populations
}

\author{
Matthew M. Marshall, ${ }^{1}$ Kristen E. Lucia, ${ }^{1}$ Jessica A. Homyack, ${ }^{2}$ \\ Darren A. Miller, ${ }^{3}$ and Matina C. Kalcounis-Rueppell ${ }^{1}$ \\ ${ }^{1}$ Department of Biology, University of North Carolina at Greensboro, Greensboro, NC 27412, USA \\ ${ }^{2}$ Timberlands Technology South, Weyerhaeuser NR Company, 1785 Weyerhaeuser Road, Vanceboro, NC 28586, USA \\ ${ }^{3}$ Timberlands Technology South, Weyerhaeuser NR Company, P.O. Box 2288, Columbus, MS 39704, USA
}

Correspondence should be addressed to Matina C. Kalcounis-Rueppell, mckalcounisrueppell@gmail.com

Received 6 October 2011; Accepted 16 January 2012

Academic Editor: Thomas V. Gallagher

Copyright (C) 2012 Matthew M. Marshall et al. This is an open access article distributed under the Creative Commons Attribution License, which permits unrestricted use, distribution, and reproduction in any medium, provided the original work is properly cited.

\begin{abstract}
Plant-based feedstocks have long been considered viable, potential sources for biofuels. However, concerns regarding production effects may outweigh gains like carbon savings. Additional information is needed to understand environmental effects of growing feedstocks, including effects on wildlife communities and populations. We used a randomized and replicated experimental design to examine initial effects of biofuel feedstock treatment options, including removal of woody biomass after clearcutting and intercropping switchgrass (Panicum virgatum), on rodents to 2 years post-treatment in regenerating pine plantations in North Carolina, USA. Rodent community composition did not change with switchgrass production or residual biomass removal treatments. Further, residual biomass removal had no influence on rodent population abundances. However, Peromyscus leucopus was found in the greatest abundance and had the greatest survival in treatments without switchgrass. In contrast, abundance of invasive Mus musculus was greatest in switchgrass treatments. Other native species, such as Sigmodon hispidus, were not influenced by the presence of switchgrass. Our results suggest that planting of switchgrass, but not biomass removal, had species-specific effects on rodents at least 2 years post-planting in an intensively managed southern pine system. Determining ecological mechanisms underlying our observed species associations with switchgrass will be integral for understanding long-term sustainability of biofuels production in southern pine forest.
\end{abstract}

\section{Introduction}

Plant-based feedstocks have long been considered viable, potential sources for biofuels, which are defined as liquid fuels derived from biological materials [1] that could displace fossil fuel consumption. However, concerns with production effects on prices of food crops, the carbon footprint of large-scale production, potential land-use change, and effects on biodiversity may outweigh gains in carbon savings or other benefits $[1,2]$. Therefore, additional information is needed related to sustainability of biofuels production and to understand environmental impacts of growing biofuel feedstocks, including impacts on biodiversity [3-5].
Source landscapes for biofuel feedstocks have expanded from agricultural to forested as technologies have developed to transform cellulosic portions of woody plants into liquid fuels at a production scale. In managed forests, biofuels typically have been produced by harvesting biomass including forest residues (i.e., tops, stumps, limbs, or unmerchantable trees that remain after harvesting and removing crop trees) or by planting short rotation woody species, such as aspen (Populus spp.) or eucalyptus (Eucalyptus spp.) [6, 7]. However, more recent efforts also have examined whether perennial grasses such as switchgrass (Panicum virgatum), a species native to eastern North America, could be intercropped between rows of crop trees in pine (Pinus spp.) plantations 
so that both traditional forest products and cellulosic energy crops could be produced on the same land base. Intercropping biofuels on managed forests may avoid concerns related to land-use change or the food versus fuel debate while still producing a carbon-neutral source of energy [1, 8]. Recently, there has been increasing interest in intercropping switchgrass within intensively managed pine stands within the southeastern United States with pilot projects being conducted to assess feasibility. For example, in 2008, Catchlight Energy LLC, a Chevron/Weyerhaeuser Joint Venture (http://www.catchlightenergy.com/), was formed in part to assess the large-scale viability of such a management system. However, environmental effects of producing biofuels from forests, either from harvesting residual woody biomass or by intercropping perennial grasses, have not been well studied $[1,6,9]$.

Rodents are model species for understanding ecological effects of anthropogenic activities for a multitude of reasons [10-12]. They contribute to species and functional diversity of the animal community [13] and are ecosystem engineers that create, modify, and maintain habitat structures (such as burrows) that influence nutrient cycling, soil aeration and habitat use by other animal species [14]. Rodents directly influence distribution and abundance of many species through their use of a variety of food sources (e.g., plants, lichen, fungi, and invertebrates) and as prey for many vertebrate predators [13].

Abundances of small mammals are influenced by changes in habitat structure, including removal of woody debris $[15,16]$ and cover of grasses $[17,18]$, so biofuels production may affect population dynamics and habitat relationships of rodents. Population abundance can be influenced by changes in habitat structure and quality, and a range of demographic parameters determines population abundance. The primary influences on population abundance are apparent survival and recruitment, which together indicate reproductive success, mortality, immigration to and emigration from a population. Additionally, adult sex ratio is important because it helps determine the effective population size. Thus, population abundance can be influenced by habitat structure, and with supporting demographic data, can be used to infer habitat quality [19]. Community composition and diversity of small mammals also vary with habitat structure [20, 21] suggesting that changes to habitat associated with biofuels production could also affect rodent diversity and abundance.

To better understand effects of producing biofuels from forested landscapes on animal communities and populations, we examined initial outcomes of a range of biofuels treatment options, including a biomass removal harvest and intercropping of switchgrass, on rodent community structure and population demographics. Population demographic parameters we examined included population abundance, recruitment, survival, and sex ratio for two years following treatment application. We hypothesized that rodent population abundance and community diversity would be greater in treatments where habitat heterogeneity was the greatest. We also hypothesized that population metrics related to habitat quality, including recruitment, survival, and male: female ratios would reflect greater habitat quality in treatments

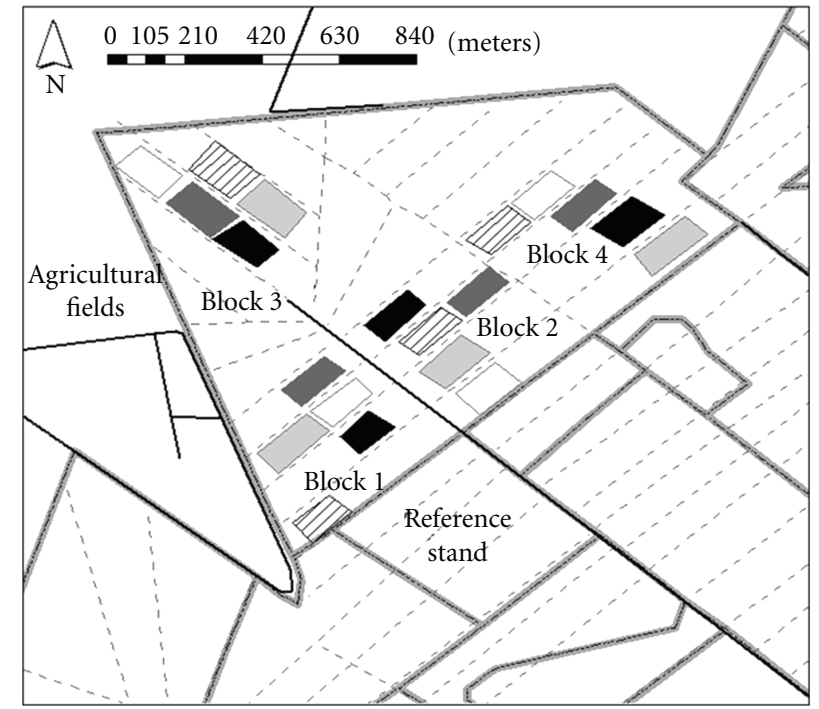

Plots treatment

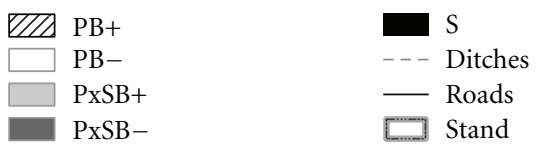

FIGURE 1: Map of study area, established and maintained by Catchlight Energy LLC, located in timberlands owned and managed by Weyerhaeuser Company in Lenoir Co., NC. Treatments: $\mathrm{PB}+=$ Pine Biomass + ; $\mathrm{PB}-=$ Pine Biomass $-; \mathrm{P} \times \mathrm{SB}+=$ Pine $\times$ Switchgrass Biomass+; $\mathrm{P} \times \mathrm{SB}-=$ Pine $\times$ Switchgrass Biomass $-; \mathrm{S}=$ Switchgrass.

where more nest sites were available, such as treatments without a biomass removal harvest. This study is the first that we are aware of to experimentally examine a range of biofuels options and their effects on rodent communities and populations.

\section{Methods}

2.1. Study Area and Experimental Design. Our study was conducted in the southeastern coastal plain on the Lenoir 1 Sustainability Study Site, established and maintained by Catchlight Energy LLC on land owned and managed by Weyerhaeuser Company in Lenoir County, North Carolina, USA. The region is sandy bottomland forest dominated by agriculture and intensively managed loblolly pine (Pinus taeda) forests. The study site was a 72-ha loblolly pine plantation established in 1974 with a site index of 70 for loblolly pine at 25 years (by 25 years of growth, loblolly pine trees can be expected to reach 70 -feet $(21.3 \mathrm{~m})$ in height due to site potential). Ground water levels were maintained via linear ditches that occurred along forest edges and paralleled each other through interiors of study site blocks (Figure 1).

Within the study site, a 33.6 ha research area was divided into 20 experimental plots that were clear-cut harvested, site prepared, and replanted with loblolly pine seedlings and/or switchgrass in 2008-09 (Figure 1). The experimental design was a randomized complete block with plots as the 
experimental unit (4 replicates) and study sites as blocks (4 study blocks and 5 treatments per block). Plots averaged 1.11 ha in size (range: $0.76-1.39$ ha: Figure 1). Within a block, experimental plots were randomly assigned one of the following five treatments:

2.1.1. Pine with Residual Woody Debris in Place, (Pine Biomass,$+ P B+$ ). Treatment plots had standard mechanical site preparation (V-shearing of stumps and roots, subsoiling, and bedding at $6.1 \mathrm{~m}$ between rows). Loblolly pines planted in December 2008 were centered on raised beds and spaced 1-2 m apart. Residual woody debris was left on site.

2.1.2. Pine with Residual Woody Debris Removed, (Pine Biomass-, $P B-$ ). Standard mechanical site preparation occurred (V-shearing of stumps and roots, subsoiling, and bedding at $6.1 \mathrm{~m}$ between rows) and pines were planted on beds 1-2 m apart. Residual woody debris was removed from the plot with an excavator to simulate a biomass harvest.

2.1.3. Pine and Switchgrass Intercropped with Residual Woody Debris in Place (Pine $\times$ Switchgrass, Biomass,$+ P \times S B+$ ). Site preparation and planting of pines followed the pine biomass + treatments. Switchgrass was machine planted in June 2009 in the alleys between rows of planted pines.

2.1.4. Pine and Switchgrass Intercropped with Residual Woody Debris Removed, (Pine $\times$ Switchgrass, Biomass-, $P \times S B-$ ). Site preparation and planting of pines followed the pine biomass treatments. Residual woody debris was removed with an excavator to simulate a biomass harvest. Switchgrass was machine planted in June 2009 in the alleys between rows of planted pines.

2.1.5. Switchgrass Only, (S). Site preparation included excavation to remove residual woody debris, $\mathrm{V}$-shearing, and root raking to establish a suitable planting surface. Switchgrass was machine-planted May-July 2009 across the entire plot.

Habitat structure of each treatment was assessed using two $30 \mathrm{~m}$ transect lines on each study plot (Figure 2) in October 2010. To estimate canopy coverage, vegetation, or woody debris that crossed transect lines and covered a minimum length of $10 \mathrm{~cm}$ along the line were measured using point interception methods [22, 23]. Percent coverage was calculated as the linear distance a habitat feature intersected the transect line divided by transect line length $(30 \mathrm{~m})$ and averaged across two transect lines per plot. Mean height of each habitat feature that intersected a transect line was estimated to the nearest $10 \mathrm{~cm}$. Height was calculated as mean height of each habitat variable on a transect line, averaged across two transect lines on each study plot.

2.2. Rodent Live Trapping. We established trapping grids $(30 \mathrm{~m} \times 60 \mathrm{~m})$ approximately $20 \mathrm{~m}$ from the edge of each study plot using four parallel trap lines with $10 \mathrm{~m}$ between traps. Each trap line was composed of six Sherman live traps (H.B. Sherman Traps Inc., Tallahassee, Florida, USA) and one randomly assigned Longworth (Rogers Manufacturing Co., Peachland, British Columbia, Canada).

We set traps at sunset (1700-2030) and checked them at sunrise (0600-0830) for three consecutive nights (henceforth referred to as a trapping period). We baited with a mixture of sunflower seeds and rolled oats. We conducted 8 trapping periods from 15 July to 9 December, 2009, and 6 trapping periods from 19 July to 14 November, 2010. We marked all rodents with a unique numbered ear-tag (Monel Numeric size 1005-1; National Band and Tag Co, Newport, Kentucky, USA). Upon capture of each rodent, we recorded ear-tag number, species, sex, age-class, reproductive condition, and mass (g). We considered P. leucopus to be adults if they had completed their post-juvenile molt [24] and S. hispidus to be adults if they weighed $>80 \mathrm{~g}$ [25]. We based age classes of other species on a combination of body mass and pelage characteristics. All rodent trapping, marking, and handling techniques were approved by the North Carolina Wildlife Resources Commission (Permit Numbers: 09-SC00162 and 10-SC00162) and the UNCG Institutional Animal Care and Use Committee (Protocol Numbers: 09-09 and 10-04).

We calculated community diversity at the plot scale with multiple metrics, including species richness (number of species captured in a plot/year), the Shannon Diversity Index, and the Fisher' $\alpha$ Diversity Index. We calculated Shannon Diversity Index as $\mathrm{H}^{\prime}$ using number of unique individuals, for each species, captured in a year [26] using Ecosim7 [27]. We calculated Fisher's $\alpha$ Diversity Index for study plots using number of unique individuals, for all species, captured in a year as $S=a+\ln (I+(n / a))$ where $S=$ species richness, $n=$ number of unique individuals, and $a=$ Fisher's $\alpha$. We used Estimate $S 8.2$ [28] with 1000 runs, strong hash encryption, and randomized samples without replacement to determine Fisher's $\alpha$ Diversity Index.

We calculated population abundance and apparent survival for all adults in the populations using Program MARK [29]. We used Pollock's robust design model (Huggins closed capture estimator-see $[30,31]$ ) to estimate population abundance during each trapping period and population survival during each intertrapping interval [32]. We used the Huggins close capture estimator because it is conditional on only animals captured and is, therefore, a more stable estimator for small sample sizes [30]. Data were grouped by species and year for analysis; the best model for each grouping was chosen based on AICc values.

In addition to examining community diversity and population abundance, we also examined sex ratio and recruitment because these demographic parameters can be influenced by habitat quality [19]. We determined sex ratio and recruitment using Program MARK. Adult sex ratio was calculated as number of adult males divided by number of adults in each population as estimated by Pollock's robust design models (Huggins closed capture estimator) with sex as a group variable. Recruitment (births and immigration) was calculated using a robust design Pradel survival and recruitment model, with Huggins closed captures estimator [33]. Due to small sample sizes when data were separated by species and plots, model selection was limited to those models with constant recruitment over time. Therefore, reported 


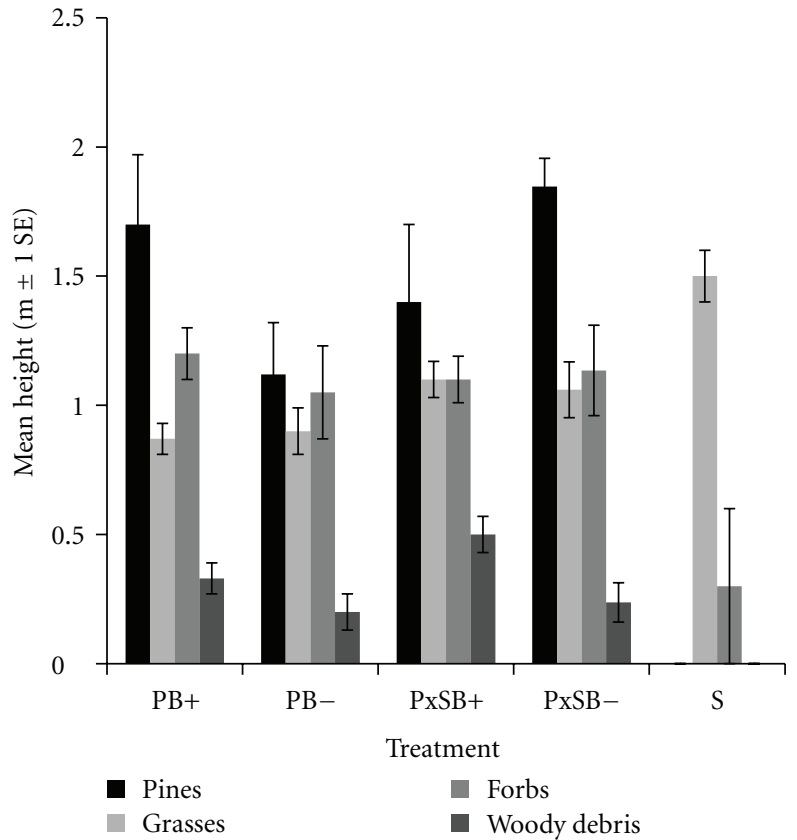

(a)

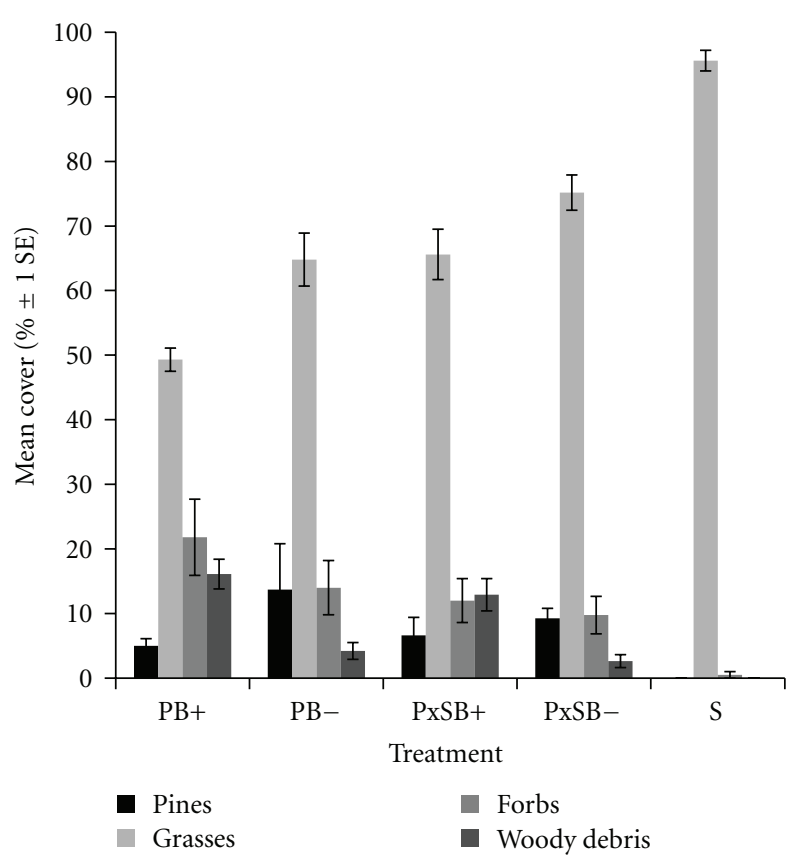

(b)

Figure 2: Mean (a) height ( $\mathrm{m} ; \pm 1$ standard error) and (b) cover $(\% ; \pm 1$ standard error) of pines, grasses, forbs, and woody debris in treatment plots at the Lenoir 1 Sustainability Study Site, in Lenoir Co, NC. Mean percent cover and mean height represent the mean value of four replicate plots based on measurements taken in October 2010. Treatments: $\mathrm{PB}+=$ Pine Biomass + ; $\mathrm{PB}-=\mathrm{Pine} \mathrm{Biomass}-; \mathrm{P} \times \mathrm{SB}+=$ Pine $\times$ Switchgrass Biomass + ; $\times$ SB $-=$ Pine $\times$ Switchgrass Biomass $-;$ S $=$ Switchgrass.

recruitment estimates represent recruitment per existing member for each plot. Parameterization of encounter probabilities ( $p$ and $c$ ) for each year-species combination matched the best fit model from the adult population abundance models.

2.3. Statistical Analyses. All dependent variables were calculated for each plot that represented an area of approximately $1,800 \mathrm{~m}^{2}$. All data are presented as mean \pm 1 standard error unless otherwise noted. We tested variables for normality using a Kolmogorov-Smirnov test and homogeneity of variance using a Levene's test. Where appropriate, we transformed variables that violated tests for normality or homogeneity of variance with $\log (+1)$, rank, square root, or square root-arcsin transformations.

We tested the hypothesis of no differences among treatments in community metrics (i.e., richness, Shannon Diversity Index, Fisher's $\alpha$ Index), abundance, recruitment, survival, and sex ratio among treatments using analysis of variance (ANOVA) or a Kruskal-Wallis test when parametric assumptions were not met. We examined relationships among population abundance and treatments by rank transforming population abundance and using an ANOVA because this facilitated a repeated measures approach [34]. For the three rodent species for which we could calculate abundance, we used repeated measures ANOVA with treatment as the between-subject factor and trapping period as the within-subject factor. In cases where the repeated measures ANOVA tests did not meet assumptions of sphericity, we used a Greenhouse-Geisser correction factor [35]. For posthoc comparisons among treatment groups, we used Tukey's analyses for ANOVA procedures and Mann-Whitney $U$ pairwise comparisons for Kruskal-Wallis procedures. We used an alpha level of 0.05 for all statistical tests and we conducted analyses with SPSS 16.0 (SPSS 2007, Chicago, Ill, USA).

\section{Results}

In 2009, we trapped small mammals on 77 nights $(15,366$ trap nights), capturing 648 unique individual rodents (267 Peromyscus leucopus, 248 Mus musculus, 122 Sigmodon hispidus, and 11 Reithrodontomys humulis) 1,806 times. In 2010, we trapped on 54 nights (11,044 trap nights) capturing 1,634 unique individual rodents (1,030 S. hispidus, $310 \mathrm{M}$. musculus, 297 P. leucopus, 15 R. humulis, and 6 Oryzomys palustris) 3,594 times. In 2009 and 2010, treatment did not influence species richness or diversity (Table 1). Sample sizes were too small for analyses for R. humulis and O. palustris.

In 2009, there was a significant effect of trapping period on $M$. musculus population abundance $\left(F_{7,105}=7.81, P<\right.$ $0.001)$ whereby a relatively small population of $M$. musculus in early trapping rounds increased through trapping periods 4 and 5 (Figure 3 ). In addition, there was a treatment effect on $M$. musculus where population abundance was less in $\mathrm{PB}+$ plots than $\mathrm{P} \times \mathrm{SB}-$ plots $\left(F_{4,15}=4.29, P=0.02\right.$; Figure 4). M. musculus population abundance was greater in treatments that contained switchgrass than treatments 
TAble 1: Mean ( \pm 1 SE) values of species richness, Shannon Diversity Index, and Fisher's $\alpha$ by treatment in 2009 and 2010 . Rodents were captured and released on site at the Lenoir 1 Sustainability Study Site, in Lenoir Co., NC, during 15 July-9 December, 2009 and 19 July-14 November, 2010. Statistical results are from comparisons using a 1-way ANOVA or Kruskal-Wallis test when parametric assumptions were not met. Kruskal-Wallis test statistics are reported as $\chi^{2}$ estimates. Treatments: $\mathrm{PB}+=$ Pine Biomass $+; \mathrm{PB}-=\mathrm{Pine} \mathrm{Biomass}-; \mathrm{P} \times \mathrm{SB}+=$ Pine $\times$ Switchgrass Biomass + ; $\times$ SB $-=$ Pine $\times$ Switchgrass Biomass $-; S=$ Switchgrass.

\begin{tabular}{|c|c|c|c|c|}
\hline Year & Treatment & Species Richness & Shannon Diversity Index & Fisher's $\alpha$ \\
\hline \multirow{6}{*}{2009} & $\mathrm{~PB}+$ & $3.25 \pm 0.25$ & $0.75 \pm 0.10$ & $0.75 \pm 0.07$ \\
\hline & $\mathrm{PB}-$ & $2.75 \pm 0.25$ & $0.62 \pm 0.19$ & $0.63 \pm 0.08$ \\
\hline & $\mathrm{P} \times \mathrm{SB}+$ & $3.25 \pm 0.48$ & $0.92 \pm 0.11$ & $0.72 \pm 0.13$ \\
\hline & $\mathrm{P} \times \mathrm{SB}-$ & $3.25 \pm 0.25$ & $0.99 \pm 0.09$ & $0.72 \pm 0.09$ \\
\hline & $S$ & $3.50 \pm 0.09$ & $0.84 \pm 0.15$ & $0.76 \pm 0.09$ \\
\hline & & $\chi^{2}=3.20, \mathrm{df}=4, P=0.53$ & $F_{4,19}=1.20, P=0.34$ & $F_{4,19}=0.31, P=0.87$ \\
\hline \multirow{6}{*}{2010} & $\mathrm{~PB}+$ & $3.00 \pm 0.0$ & $0.78 \pm 0.09$ & $0.55 \pm 0.01$ \\
\hline & $\mathrm{PB}-$ & $3.50 \pm 0.29$ & $0.91 \pm 0.07$ & $0.66 \pm 0.07$ \\
\hline & $\mathrm{P} \times \mathrm{SB}+$ & $3.50 \pm 0.29$ & $0.86 \pm 0.14$ & $0.65 \pm 0.08$ \\
\hline & $\mathrm{P} \times \mathrm{SB}-$ & $3.75 \pm 0.25$ & $0.76 \pm 0.15$ & $0.69 \pm 0.07$ \\
\hline & S & $3.50 \pm 0.29$ & $0.89 \pm 0.08$ & $0.67 \pm 0.07$ \\
\hline & & $\chi^{2}=4.61, \mathrm{df}=4, P=0.33$ & $F_{4,19}=0.40, P=0.80$ & $\chi^{2}=1.02, \mathrm{df}=4, P=0.91$ \\
\hline
\end{tabular}

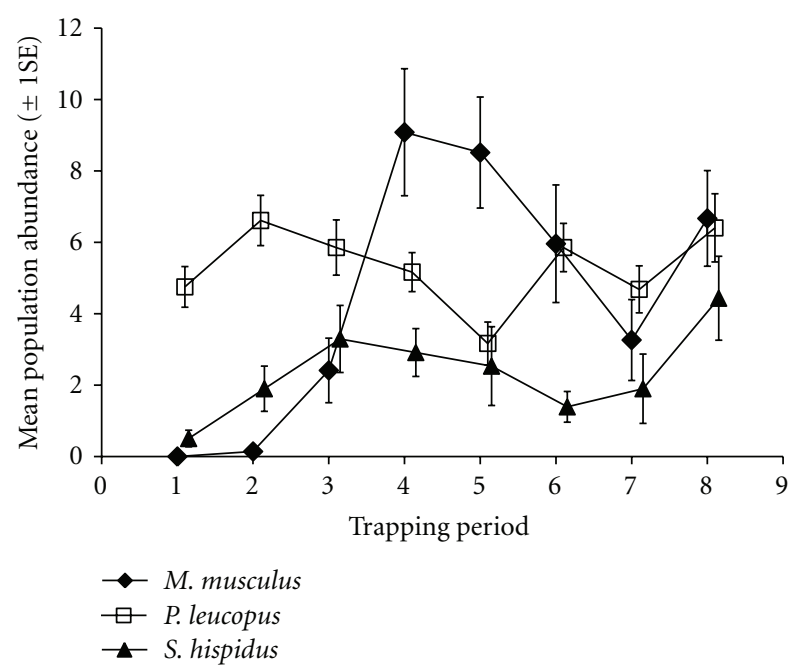

(a) 2009

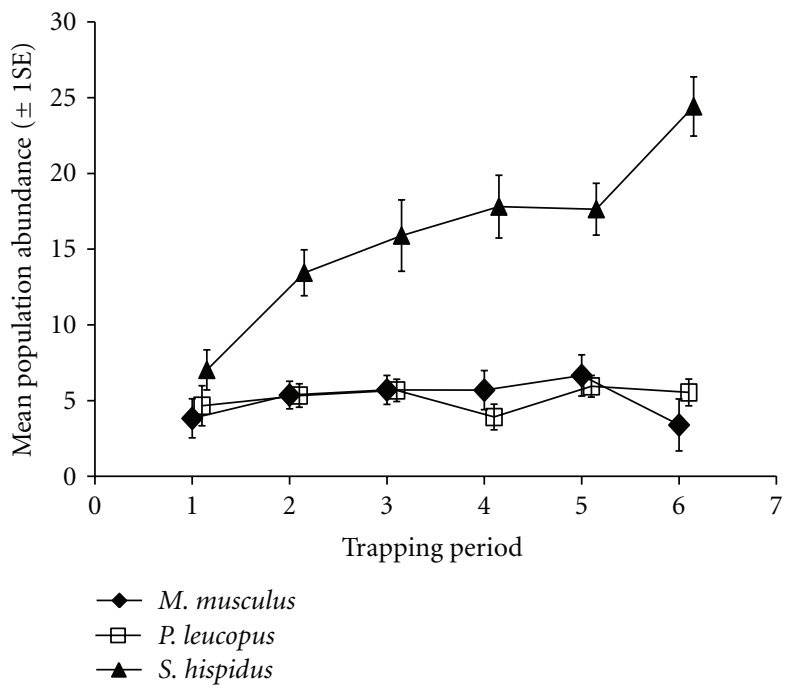

(b) 2010

FIgure 3: Population abundance (mean abundance \pm 1 standard error; $n=4$ ) for Mus musculus, Peromyscus leucopus, and Sigmodon hispidus by trapping period in (a) 2009 and (b) 2010 at the Lenoir 1 Sustainability Study Site, in Lenoir Co., NC. Axes vary between plot (a) and (b) to improve readability. Although not shown, 18 Reithrodontomys humulis were captured in 2009: 1 in period 2 (P2), 3 in P3, 2 in P4, 2 in P5, 5 in P6, 3 in P7, and 2 in P8. Sixteen R. humulis were captured in 2010 (3 in P3, 3 in P4, 3 in P5, and 7 in P6). Additionally, 6 Oryzomys palustris were captured in the last trapping periods of 2010. Rodents were captured and released during 15 July-9 December, 2009 and 19 July-14 November, 2010.

that did not, although not all pairwise comparisons were significant (Figure 4). P. leucopus population abundance did not differ among trapping periods $\left(F_{7,105}=0.13, P=1.00\right.$; Figure 3) nor treatments $\left(F_{4,15}=0.88, P=0.50\right.$; Figure 4$)$. $S$. hispidus population abundance did not differ among trapping periods $\left(F_{3.49,52.38}=1.21, P=0.32\right.$; Figure 3$)$ nor treatments $\left(F_{4,15}=0.53, P=0.72\right.$; Figure 4$)$.

Population abundances were not influenced by trapping period in 2010 (M. musculus: $F_{5,75}=0.21, P=0.96$; $P$. leucopus: $F_{2.73,40.90}=0.03, P=0.99 ; S$. hispidus: $F_{1.72,40.89}=0.11$, 

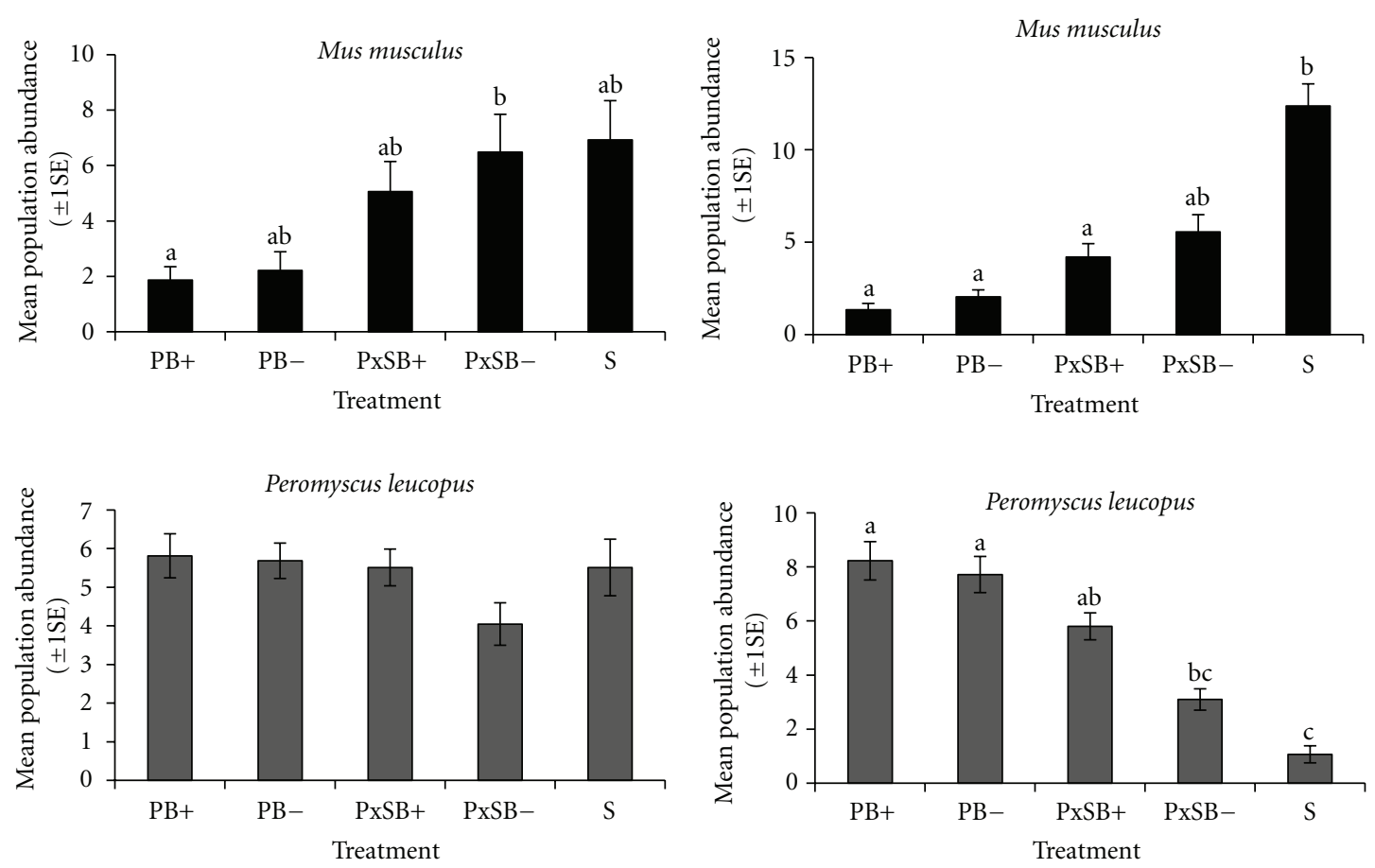

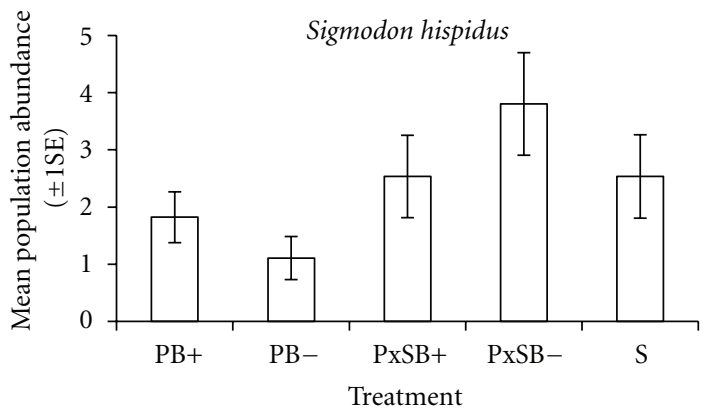

(a) 2009

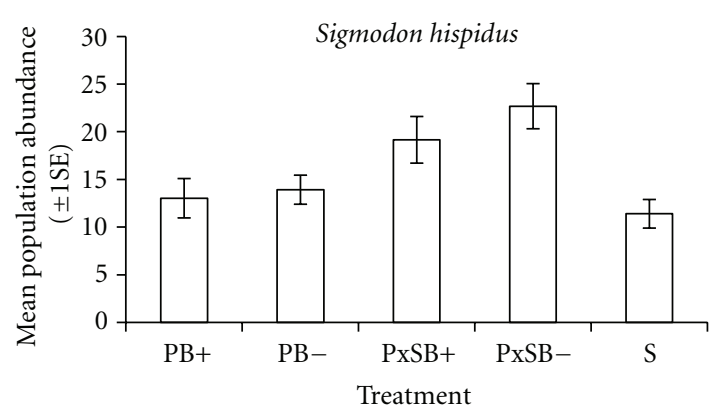

(b) 2010

FIGURE 4: Population abundance estimates from Program MARK (mean number of adult individuals/plot, \pm 1 standard error; $n=4$ ) for Mus musculus, Peromyscus leucopus, and Sigmodon hispidus by treatment in (a) 2009 and (b) 2010 at the Lenoir 1 Sustainability Study Site, in Lenoir Co, NC. $y$-axes vary between plot (a) and (b) to improve readability. Treatments: PB+ = Pine Biomass+; PB- = Pine Biomass-; $\mathrm{P} \times \mathrm{SB}+=$ Pine $\times$ Switchgrass Biomass $+\mathrm{P} \times \mathrm{SB}-=$ Pine $\times$ Switchgrass Biomass $-; \mathrm{S}=$ Switchgrass. Treatments with different letters are significantly different $(P<0.05$; Tukey's post hoc tests). Rodents were captured and released during 15 July-9 December, 2009 and 19 July-14 November, 2010.

$P=0.94 ;$ Figure 3). M. musculus population abundance was greatest in switchgrass only plots $\left(F_{4,15}=8.25, P<0.001\right.$; Figure 4). In contrast, population abundance was the lowest for $P$. leucopus in switchgrass only plots and the greatest in plots without switchgrass $(\mathrm{PB}+$ and $\mathrm{PB}-)$, although not all pairwise comparisons showed significant differences $\left(F_{4,15}=13.61, P<0.001\right.$; Figure 4$) . S$. hispidus population abundance did not differ among treatments $\left(F_{4,15}=1.40\right.$, $P=0.28$; Figure 4).

There was no influence of treatment on recruitment of M. musculus, P. leucopus, or S. hispidus in either year (Table 2). Survival of $P$. leucopus was less in the pure switchgrass treatment than in treatments without switchgrass in 2010 (PB-, PB+; Table 3). Treatments also influenced sex ratio where there were fewer $M$. musculus males in $\mathrm{PB}+$ than $\mathrm{PB}$ - treatments in 2010 (Table 4).

\section{Discussion}

Our results suggest that community composition of rodents did not change due to switchgrass intercropping or biomass removal treatments. However, there were species level responses to switchgrass whereby more $P$. leucopus were in plots without switchgrass and more M. musculus in plots with switchgrass. Additionally, decreased apparent survival of $P$. leucopus in switchgrass suggests that individual $P$. leucopus that did move into switchgrass was either less likely to survive or more likely to permanently emigrate from those treatments. This finding contrasts with higher apparent survival of $P$. leucopus in $\mathrm{PB}-$ and $\mathrm{PB}+$ treatments (treatments without switchgrass), where they experienced either decreased mortality or decreased likelihood of permanent emigration from those treatments. 
TABLE 2: Mean ( $\pm 1 \mathrm{SE})$ recruitment estimates (new individual via birth or immigration/existing member/plot) by treatment (calculated in Program MARK). Rodents were captured and released on site at the Lenoir 1 Sustainability Study Site, in Lenoir Co., NC, during 15 July-9 December, 2009 and 19 July-14 November, 2010. Statistical results are from comparisons using a 1-way ANOVA or Kruskal-Wallis test when parametric assumptions were not met. Kruskal-Wallis test statistics are reported as $\chi^{2}$ estimates. Treatments: $\mathrm{PB}+=\mathrm{Pine}$ Biomass + ; $\mathrm{PB}-=$ Pine Biomass $-; \mathrm{P} \times \mathrm{SB}+=$ Pine $\times$ Switchgrass Biomass + ; $\times \mathrm{SB}-=$ Pine $\times$ Switchgrass Biomass $-; \mathrm{S}=$ Switchgrass.

\begin{tabular}{ccccc}
\hline Year & Treatment & M. musculus & P. leucopus & S. hispidus \\
\hline & $\mathrm{PB}+$ & $0.24 \pm 0.14$ & $0.03 \pm 0.01$ & $0.10 \pm 0.07$ \\
2009 & $\mathrm{~PB}-$ & $0.44 \pm 0.15$ & $0.03 \pm 0.00$ & $0.73 \pm 0.25$ \\
& $\mathrm{P} \times \mathrm{SB}+$ & $0.27 \pm 0.19$ & $0.03 \pm 0.00$ & $0.06 \pm 0.23$ \\
& $\mathrm{P} \times \mathrm{SB}-$ & $0.10 \pm 0.01$ & $0.03 \pm 0.01$ & $0.44 \pm 0.23$ \\
$\mathrm{~S}$ & $0.20 \pm 0.14$ & $0.03 \pm 0.01$ & $0.79 \pm 0.77$ \\
\hline & & $F_{4,19}=0.80, P=0.54$ & $F_{4,19}=0.19, P=0.94$ & $0.05 \pm 0.01$ \\
2010 & & $0.22 \pm 0.16$ & $0.02 \pm 0.00$ & $0.04 \pm 0.00$ \\
& $\mathrm{~PB}+$ & $0.22 \pm 0.12$ & $0.03 \pm 0.00$ & $0.04 \pm 0.01$ \\
& $\mathrm{~PB}-$ & $0.07 \pm 0.02$ & $0.21 \pm 0.18$ & $0.03 \pm 0.00$ \\
& $\mathrm{P} \times \mathrm{SB}+$ & $0.20 \pm 0.11$ & $0.24 \pm 0.19$ & $0.05 \pm 0.01$ \\
\hline & $\mathrm{P} \times \mathrm{SB}-$ & $0.06 \pm 0.01$ & $\chi^{2}=5.73, \mathrm{df}=4, P=0.22$ & $\chi^{2}=3.96, \mathrm{df}=4, P=0.41$ \\
\hline
\end{tabular}

TABLE 3: Mean ( $\pm 1 S E)$ survival estimates for intertrapping period intervals by treatment (averaged across time and plots within treatment; calculated in Program MARK). Rodents were captured and released on site at the Lenoir 1 Sustainability Study Site, in Lenoir Co., NC, during 15 July-9 December, 2009 and 19 July-14 November, 2010. Statistical results are from comparisons using a 1-way ANOVA or Kruskal-Wallis test when parametric assumptions were not met. Kruskal-Wallis test statistics are reported as $\chi^{2}$ estimates. Within a year-species pairing, means with different letters are significantly different from one another (Tukey's post hoc tests). Treatments: $\mathrm{PB}+=\mathrm{Pine}$ Biomass + ; $\mathrm{PB}-=$ Pine Biomass $-; \mathrm{P} \times \mathrm{SB}+=$ Pine $\times$ Switchgrass Biomass + ; $\mathrm{P} \times \mathrm{SB}-=$ Pine $\times$ Switchgrass Biomass $-; \mathrm{S}=$ Switchgrass.

\begin{tabular}{ccccc}
\hline Year & Treatment & M. musculus & P. leucopus & S. hispidus \\
\hline \multirow{4}{*}{2009} & $\mathrm{~PB}+$ & $0.46 \pm 0.03$ & $0.93 \pm 0.04$ & $0.57 \pm 0.06$ \\
& $\mathrm{~PB}-$ & $0.51 \pm 0.04$ & $0.92 \pm 0.04$ & $0.39 \pm 0.03$ \\
& $\mathrm{P} \times \mathrm{SB}+$ & $0.56 \pm 0.05$ & $0.92 \pm 0.04$ & $0.53 \pm 0.06$ \\
& $\mathrm{P} \times \mathrm{SB}-$ & $0.57 \pm 0.05$ & $0.93 \pm 0.03$ & $0.53 \pm 0.05$ \\
\hline $\mathrm{S}$ & $0.66 \pm 0.05$ & $0.87 \pm 0.05$ & $0.60 \pm 0.06$ \\
\hline & & $F_{4,15}=0.85, P=0.51$ & $F_{4,15}=0.14, P=0.97$ & $F_{4,12}=1.29, P=0.33$ \\
\hline \multirow{4}{*}{2010} & $\mathrm{~PB}+$ & $0.49 \pm 0.07$ & $0.98 \pm 0.00^{\mathrm{a}}$ & $0.93 \pm 0.04$ \\
& $\mathrm{~PB}-$ & $0.50 \pm 0.06$ & $0.99 \pm 0.00^{\mathrm{a}}$ & $0.95 \pm 0.03$ \\
& $\mathrm{P} \times \mathrm{SB}+$ & $0.67 \pm 0.07$ & $0.93 \pm 0.04^{\mathrm{a}}$ & $0.96 \pm 0.03$ \\
& $\mathrm{P} \times \mathrm{SB}-$ & $0.59 \pm 0.07$ & $0.75 \pm 0.07^{\mathrm{ab}}$ & $0.99 \pm 0.00$ \\
$\mathrm{~S}$ & & $0.81 \pm 0.06$ & $0.56 \pm 0.06^{\mathrm{b}}$ & $0.97 \pm 0.01$ \\
\hline
\end{tabular}

Rodent species captured in this study were expected to be found inhabiting pine forests in the southeast [15, 17, 36, 37]. Peromyscus leucopus, S. hispidus, R. humulis, and M. musculus were the only species captured in study plots in the first year of study and were $>99 \%$ of the individuals captured in the second year of study (6 O. palustris were captured during November 2010).

The most abundant species captured shifted from $P$. leucopus in 2009 to S. hispidus in 2010. Both years of the study experienced similar weather, and there were no discrete weather events that would explain the patterns of population abundance we saw between years. Rather, shifts in species relative population abundance between years is likely due to successional changes, and has been observed in other studies of young pine plantations in the southeastern USA, and in secondary succession of both forest and grassland habitat types $[36,38,39]$. Sigmodon hispidus prefers grassy understory $[40,41]$, which was not available on study plots until 2010. This shift from P. leucopus to S. hispidus being the most abundant species suggests the rodent community responded to changes that occurred in habitat structure between site preparation at the beginning of year one and treatment establishment.

Our treatments varied along two resource axes: residual pine biomass (i.e., coarse woody debris; CWD) and switchgrass presence. Our results suggest that retention of biomass did not influence rodents within the first two years postsite preparation in this system because, overall, treatments with 
TABLE 4: Mean $( \pm 1 S E)$ values of sex ratio (proportion males) from adult population abundance estimates calculated in Program MARK. Rodents were captured and released on site at the Lenoir 1 Sustainability Study Site, in Lenoir Co., NC, during 15 July-9 December, 2009 and 19 July-14 November, 2010. Statistical results are from comparisons using a 1-way ANOVA or Kruskal-Wallis test when parametric assumptions were not met. Kruskal-Wallis test statistics are reported as $\chi^{2}$ estimates. Within a year-species pairing, means with different letters are significantly different from one another (Mann-Whitney $U$ pairwise comparisons with Bonferroni correction). Treatments: $\mathrm{PB}+=$ Pine Biomass+; $\mathrm{PB}-=$ Pine Biomass $-; \mathrm{P} \times \mathrm{SB}+=$ Pine $\times$ Switchgrass Biomass $+; \mathrm{P} \times \mathrm{SB}-=$ Pine $\times$ Switchgrass Biomass $-; \mathrm{S}=$ Switchgrass.

\begin{tabular}{ccccc}
\hline Year & Treatment & M. musculus & P. leucopus & S. hispidus \\
\hline \multirow{2}{*}{2009} & $\mathrm{~PB}+$ & $0.72 \pm 0.09$ & $0.65 \pm 0.04$ & $0.49 \pm 0.12$ \\
& $\mathrm{~PB}-$ & $0.57 \pm 0.11$ & $0.57 \pm 0.05$ & $0.44 \pm 0.12$ \\
& $\mathrm{P} \times \mathrm{SB}+$ & $0.65 \pm 0.08$ & $0.60 \pm 0.04$ & $0.58 \pm 0.09$ \\
& $\mathrm{P} \times \mathrm{SB}-$ & $0.61 \pm 0.07$ & $0.61 \pm 0.06$ & $0.38 \pm 0.19$ \\
$\mathrm{~S}$ & $0.52 \pm 0.08$ & $0.62 \pm 0.04$ & $0.74 \pm 0.09$ \\
\hline & & $F_{4,19}=0.35, P=0.84$ & $\chi^{2}=0.27, \mathrm{df}=4, P=0.99$ & $F_{4,19}=0.63, P=0.65$ \\
\hline \multirow{2}{*}{2010} & $\mathrm{~PB}+$ & $0.44 \pm 0.12^{\mathrm{a}}$ & $0.62 \pm 0.04$ & $0.63 \pm 0.04$ \\
& $\mathrm{~PB}-$ & $0.81 \pm 0.08^{\mathrm{b}}$ & $0.55 \pm 0.03$ & $0.55 \pm 0.04$ \\
& $\mathrm{P} \times \mathrm{SB}+$ & $0.40 \pm 0.09^{\mathrm{ab}}$ & $0.79 \pm 0.04$ & $0.43 \pm 0.04$ \\
& $\mathrm{P} \times \mathrm{SB}-$ & $0.60 \pm 0.06^{\mathrm{ab}}$ & $0.60 \pm 0.07$ & $0.43 \pm 0.05$ \\
$\mathrm{~S}$ & $0.64 \pm 0.04^{\mathrm{ab}}$ & $0.42 \pm 0.13$ & $0.61 \pm 0.05$ \\
\hline
\end{tabular}

biomass removal had similar rodent abundances compared to treatments without biomass removal. A recent metaanalysis indicated little or no consistent response of mammal diversity to CWD and suggests that small mammal response to CWD is very context dependent. We were not able to find a relationship between small mammal metrics and removal of biomass in this study, which is consistent with other studies in the southeastern USA. At this time, it is unclear if a greater range of removal levels or a greater range in CWD amounts among treatments would have caused a stronger small mammal response [42]. Although biomass provides important habitat structure (i.e., nest sites, foraging substrate, and cover from predators) for rodents, it is likely that other factors such as presence of switchgrass (i.e., a potential source of food and cover) exerted a greater influence during early succession in this managed pine forest.

Presence of switchgrass changed habitat structure and resources available to the rodent community in young managed pine stands during the first two years of growth [43]. Differences in habitat structure among treatments with and without switchgrass were reflected in rodent population responses within the first year of study and became more pronounced in the second year of the study. While there was no effect of treatment on sex ratio or recruitment, population abundance and survival data suggest that $P$. leucopus was negatively affected by switchgrass presence. During the second year of study, P. leucopus adults were found in greatest abundance in $\mathrm{PB}+$ and $\mathrm{PB}-$ treatments (nonswitchgrass treatments) and had greater apparent survival (mortality and permanent emigration) in these plots. Our results suggest that individual $P$. leucopus in plots with switchgrass ( $\mathrm{P}$ $\times \mathrm{SB}-$ and $\mathrm{S}$ ) were either less likely to survive or more likely to permanently emigrate from the habitat. In contrast, $P$. leucopus in $\mathrm{PB}+$ and $\mathrm{PB}-$ habitat experienced either decreased mortality or decreased likelihood of permanent emigration from the habitat. Peromyscus leucopus is typically an early successional species that is more abundant in open habitat types than areas with greater understory foliage cover $[36,44]$. In our study, plots with switchgrass contained dense switchgrass cover. Our results suggest that switchgrassdominated understories may not provide sufficient resources to support $P$. leucopus and/or that $P$. leucopus may be outcompeted by M. musculus in these treatments. However, additional research is needed to determine if this effect is temporary, if it changes with further stand development, and the causal mechanisms of this effect.

In contrast to our findings for P. leucopus, the population abundance of $M$. musculus was positively affected by switchgrass. During the first year of study, there were more M. musculus in the $\mathrm{P} \times \mathrm{SB}-$ and $\mathrm{S}$ plots than the other plots, and by the second year of study, there were over twice as many adults captured in switchgrass only plots than any other treatment. Additionally, M. musculus abundance in the intercropping treatments was intermediate to either $\mathrm{S}$ or $\mathrm{PB}+/ \mathrm{PB}-$ treatments. However, there was no effect of treatment on the apparent survival or recruitment (per capita births and immigration) of $M$. musculus. Therefore, while more $M$. musculus individuals were found in switchgrass treatments, the proportional population dynamics were similar among treatments-M. musculus were not more or less likely to survive, reproduce, immigrate or emigrate from any treatment. Yet in the second year, the adult populations of M. musculus in $\mathrm{PB}-$ were male dominated, the populations in $\mathrm{PB}+$ had even sex ratios and the switchgrass treatments were intermediate between the two pine treatments. These findings suggest that female $M$. musculus may have been differentially affected by the presence of biomass in their less preferred habitat.

Mus musculus is an introduced, invasive species that can increase in abundance rapidly when required resources become available [44]. In the first year of our study, $M$. musculus abundance increased across trapping periods from 
July-December 2009. Appearance of M. musculus in study plots in late August 2009 occurred simultaneously with harvest of corn (Zea mays) fields located adjacent to the north and east borders of our study area (Figure 1). Based on initial captures, abundance of M. musculus adults increased, suggesting an initial immigration event occurred on the study site from adjacent agricultural fields. Additional support for the immigration of $M$. musculus onto the study site from agricultural fields comes from our trapping data that shows individuals were first captured at trap stations close to the adjacent corn fields.

There was no treatment effect on population abundance of S. hispidus in either year of our study. Additionally, there was no treatment effect on S. hispidus recruitment, apparent survival, or sex ratio. However, population abundances in the second year of our study were approximately four to ten times greater than the population abundances in the same treatments in the first year of our study, and while not significant, S. hispidus population abundances were numerically greatest in $\mathrm{P} \times \mathrm{SB}-$ plots during both years. S. hispidus is associated with early successional or disturbed habitat types that have greater understory cover [17]. Furthermore, S. hispidus can out-compete other rodent species for resources in habitat types with greater understory foliage cover [36, 45, 46], Our results suggest that in more complex habitat, and as habitat heterogeneity increased from the first to second year of the study, S. hispidus was able to out-compete other species and become dominant. However, understanding effects of competition versus successional change in community structure would require additional studies.

During both years of our study, few $R$. humulis were captured, which was unsurprising given that it is a relatively rare species in pine forests [36]. Nevertheless, we captured $R$. humulis individuals in all treatment options at low numbers suggesting that for at least two years postpreparation, presence of switchgrass does not influence abundance of this species relative to nonswitchgrass plots. This result was surprising because we expected $R$. humulis to increase in presence of switchgrass due to increased availability of seeds during autumn and granivorous habits of $R$. humulis. Lack of response of $R$. humulis abundance suggests this species does not respond rapidly to changes in resource abundance or may be locally rare in managed pine forests in our study area. Data from other studies in the coastal plain suggest the former; $R$. humulis are among the most commonly captured species in the southeastern coastal plain $[17,37,46]$ but are captured at relatively low rates after initial stand establishment [37].

Our results suggest either that $P$. leucopus is more competitive in plots with pine and M. musculus is more competitive in plots with switchgrass or that switchgrass does not provide suitable resources for $P$. leucopus and plots with pine do not provide suitable resources for M. musculus. Evidence from studies of mammalian diversity in pine plantations suggests that, although M. musculus is present, it is not usually the most abundant small mammal species present (e.g., $[36,45])$. However, the potential mechanisms underlying our observed patterns, especially the clearly opposite responses of $P$. leucopus and M. musculus to switchgrass treatments, require further investigation. Field experiments involving competitor exclusion or limited-resource provision could be used to determine ecological mechanisms underlying the responses of P. leucopus and M. musculus to the presence of switchgrass in the future.

\section{Implications}

(1) Our results suggest residual biomass removal has no influence on rodent community structure or population demographics in an intensively managed, coastal plain southern pine system.

(2) In our study, switchgrass has a positive influence on the invasive M. musculus and a negative influence on the native P. leucopus. Moreover, intercropping switchgrass with pine does not appear to completely offset effects of switchgrass, at least for P. leucopus. However, other native species, such as S. hispidus, were not influenced by presence of switchgrass. In the short term, switchgrass can affect abundance of native and invasive rodent species. Determining ecological effects underlying associations is important for long-term implications.

\section{Acknowledgments}

Financial and logistical support was provided by Catchlight Energy LLC, University of North Carolina at Greensboro, and Weyerhaeuser Company. J. A. Homyack and D. A. Miller provided support under a Statement of Work as Service Providers for Catchlight Energy LLC during this research. The authors thank J. R. Briggs, K. M. Briones, R. Petric, and M. Wallrichs for help in the field. The authors thank K. King, A. Mattesson, and T. Weiler for help with the trapping record database and K. Mabry for assistance with Program MARK. K. M. Briones, G. Wasserberg, S. Faeth, and two anonymous reviewers provided comments that improved previous versions of this manuscript.

\section{References}

[1] V. Dale, K. Kline, J. Wiens, and J. Fargione, "Biofuels: implications for land use and biodiversity," Biofuels and Sustainability Reports, pp. 1-13, 2010.

[2] T. Searchinger, R. Heimlich, R. A. Houghton et al., "Use of U.S. croplands for biofuels increases greenhouse gases through emissions from land-use change," Science, vol. 319, no. 5867, pp. 1238-1240, 2008.

[3] R. J. Fletcher Jr., B. A. Robertson, J. Evans, P. J. Doran, J. R. R. Alavalapati, and D. W. Schemske, "Biodiversity conservation in the era of biofuels: risks and opportunities," Frontiers in Ecology and the Environment, vol. 9, no. 3, pp. 161-168, 2011.

[4] L. Bies, "The biofuels explosion: is green energy good for wildlife?" Wildlife Society Bulletin, vol. 34, no. 4, pp. 12031205, 2006.

[5] J. van Dam, M. Junginger, and A. P. C. Faaij, "From the global efforts on certification of bioenergy towards an integrated approach based on sustainable land use planning," Renewable and Sustainable Energy Reviews, vol. 14, no. 9, pp. 2445-2472, 2010. 
[6] J. G. Benjamin, R. J. Lilieholm, and C. E. Coup, "Forest biomass harvesting in the Northeast: a special-needs operation," Northern Journal of Applied Forestry, vol. 27, no. 2, pp. 45-49, 2010.

[7] S. Riffell, J. Verschuyl, D. Miller, and T. B. Wigley, "A metaanalysis of bird and mammal response to short-rotation woody crops," GCB Bioenergy, vol. 3, pp. 313-321, 2011.

[8] J. Fargione, J. Hill, D. Tilman, S. Polasky, and P. Hawthorne, "Land clearing and the biofuel carbon debt," Science, vol. 319, no. 5867, pp. 1235-1238, 2008.

[9] S. Riffell, J. Verschuyl, D. Miller, and T. B. Wigley, "Potential biodiversity response to intercropping herbaceous biomass crops on forest lands," Journal of Forestry, vol. 110, no. 1, pp. 42-47, 2012.

[10] C. Maser, J. M. Trappe, and R. A. Nussbaum, "Fungal-small mammal interrelationships with emphasis on Oregon coniferous forests," Ecology, vol. 59, pp. 799-809, 1978.

[11] F. Dibello, S. Arthur, and W. Krohn, "Food habits of sympatric coyotes, Canis latrans, red foxes, Vulpes vulpes, and bobcats, Lynx rufus, in Maine," Canadian Field-Naturalist, vol. 104, pp. 403-408, 1990.

[12] A. D. Davidson and D. C. Lightfoot, "Burrowing rodents increase landscape heterogeneity in a desert grassland," Journal of Arid Environments, vol. 72, no. 7, pp. 1133-1145, 2008.

[13] A. B. Carey and M. L. Johnson, "Small mammals in managed, naturally young, and old-growth forests," Ecological Applications, vol. 5, no. 2, pp. 336-352, 1995.

[14] C. G. Jones, J. H. Lawton, and M. Shachak, "Organisms as ecosystem engineers," Oikos, vol. 69, no. 3, pp. 373-386, 1994.

[15] S. C. Loeb, "Responses of small mammals to coarse woody debris in a Southeastern pine forest," Journal of Mammalogy, vol. 80, no. 2, pp. 460-471, 1999.

[16] J. C. Davis, S. B. Castleberry, and J. C. Kilgo, "Influence of coarse woody debris on the soricid community in southeastern Coastal Plain pine stands," Journal of Mammalogy, vol. 91, no. 4, pp. 993-999, 2010.

[17] M. T. Mengak and D. C. Guynn, "Small mammal microhabitat use on young loblolly pine regeneration areas," Forest Ecology and Management, vol. 173, no. 1-3, pp. 309-317, 2003.

[18] A. D. Davidson, E. Ponce, D. C. Lightfoot et al., "Rapid response of a grassland ecosystem to an experimental manipulation of a keystone rodent and domestic livestock," Ecology, vol. 91, no. 11, pp. 3189-3200, 2010.

[19] B. Van Horne, "Density as a misleading indicator of habitat quality," Journal of Wildlife Management, vol. 47, no. 4, pp. 893-901, 1983.

[20] W. E. Grant and E. C. Birney, "Small mammal community structure in North American grasslands," Journal of Mammalogy, vol. 60, pp. 23-36, 1979.

[21] S. E. Williams, H. Marsh, and J. Winter, "Spatial scale, species diversity, and habitat structure: small mammals in Australian tropical rain forest," Ecology, vol. 83, no. 5, pp. 1317-1329, 2002.

[22] D. A. Floyd and J. E. Anderson, "A comparison of three methods for estimating plant cover," Journal of Ecology, vol. 75, no. 1, pp. 221-228, 1987.

[23] C. E. Braun, Ed., Techniques for Wildlife Investigations and Management, Wildlife Society, Bethesda, Md, USA, 6th edition, 2005.

[24] J. Layne, "Ontogeny," Biology of Peromyscus, pp. 148-253, 1968.
[25] R. K. Chipman, F. M. Nahhas, and R. B. Short, Age Determination of the Cotton Rat (Sigmodon hispidus), Tulane University, 1965.

[26] C. E. Shannon, "A mathematical theory of communication," Bell System Technical Journal, vol. 27, pp. 623-656, 1948.

[27] N. J. Gotelli and G. L. Entsminger, "Ecosim: null models software for ecology," 2009, http://garyentsminger.com/.

[28] R. Colwell, EstimateS 8.2: Statistical Estimation of Species Richness and Shared Species from Samples. User's Guide and Application, Department of Ecology and Evolutionary Biology, University of Connecticut, Storrs, Conn, USA, 2009.

[29] G. C. White and K. P. Burnham, "Program MARK: survival estimation from populations of marked animals," Bird Study, vol. 46, pp. S120-S139, 1999.

[30] R. M. Huggins, "Some practical aspects of a conditional likelihood approach to capture experiments," Biometrics, vol. 47, no. 2, pp. 725-732, 1991.

[31] R. M. Huggins, "On the statistical analysis of capture experiments," Biometrika, vol. 76, no. 1, pp. 133-140, 1989.

[32] W. L. Kendall, "The robust design for capture-recapture studies: analysis using Program MARK," in Wildlife, Land, and People: Priorities for the 21st Century, R. Warren, H. Okarma, and P. Sievert, Eds., pp. 357-360, The Wildlife Society, Bethesda, Md, USA, 2001.

[33] R. Pradel, "Utilization of capture-mark-recapture for the study of recruitment and population growth rate," Biometrics, vol. 52, no. 2, pp. 703-709, 1996.

[34] W. J. Conover and R. L. Iman, "Analysis of covariance using the rank transformation," Biometrics, vol. 38, no. 3, pp. 715724,1982 .

[35] S. W. Greenhouse and S. Geisser, "On methods in the analysis of profile data," Psychometrika, vol. 24, no. 2, pp. 95-112, 1959.

[36] T. D. Atkeson and A. S. Johnson, "Succession of small mammals on pine plantations in the Georgia piedmont," American Midland Naturalist, vol. 101, pp. 385-392, 1979.

[37] V. Lane, Plant, small mammal, and bird community responses to a gradient of site preparation intensities in pine plantations in the coastal plain of North Carolina, thesis, Univeristy of Georgia, Athens, Ga, USA, 2010.

[38] P. Masters, "The effects of fire-driven succession and rainfall on small mammals in spinifex grassland at Uluru National Park, Northern Territory," Wildlife Research, vol. 20, no. 6, pp. 803-813, 1993.

[39] D. J. Clarke and J. G. White, "Recolonisation of powerline corridor vegetation by small mammals: timing and the influence of vegetation management," Landscape and Urban Planning, vol. 87, no. 2, pp. 108-116, 2008.

[40] E. R. Hall, The Mammals of North America, vol. 2, Wiley, 1981.

[41] B. J. Bergstrom and R. K. Rose, "Comparative life histories of Georgia and Virginia cotton rats," Journal of Mammalogy, vol. 85, no. 6, pp. 1077-1086, 2004.

[42] S. Riffell, J. Verschuyl, D. Miller, and T. B. Wigley, "Biofuel harvests, coarse woody debris, and biodiversity - A meta-analysis," Forest Ecology and Management, 2011.

[43] M. Marshall, The influence of managing a loblolly pine (Pinus taeda) forest for biofuels production via switchgrass (Panicum virgatum L.) intercropping and woody debris removal on rodents, thesis, University of North Carolina at Greensboro, Greensboro, NC, USA, 2011.

[44] N. C. Stenseth, H. Leirs, A. Skonhoft et al., "Mice, rats, and people: the bio-economics of agricultural rodent pests," Frontiers in Ecology and the Environment, vol. 1, pp. 367-375, 2003. 
[45] M. S. Mitchell, K. S. Karriker, E. J. Jones, and R. A. Lancia, "Small mammal communities associated with pine plantation management of pocosins," Journal of Wildlife Management, vol. 59, no. 4, pp. 875-881, 1995.

[46] N. L. Constantine, T. A. Campbell, W. M. Baughman, T. B. Harrington, B. R. Chapman, and K. V. Miller, "Small mammal distributions relative to corridor edges within intensively managed southern pine plantations," Southern Journal of Applied Forestry, vol. 29, no. 3, pp. 148-151, 2005. 

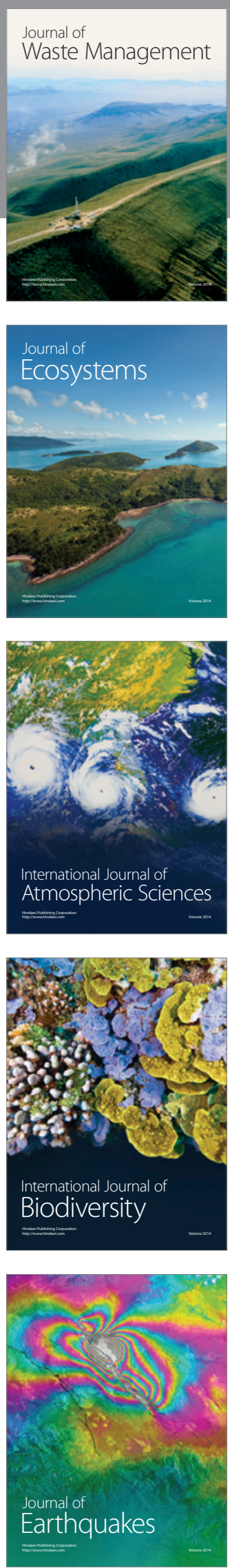
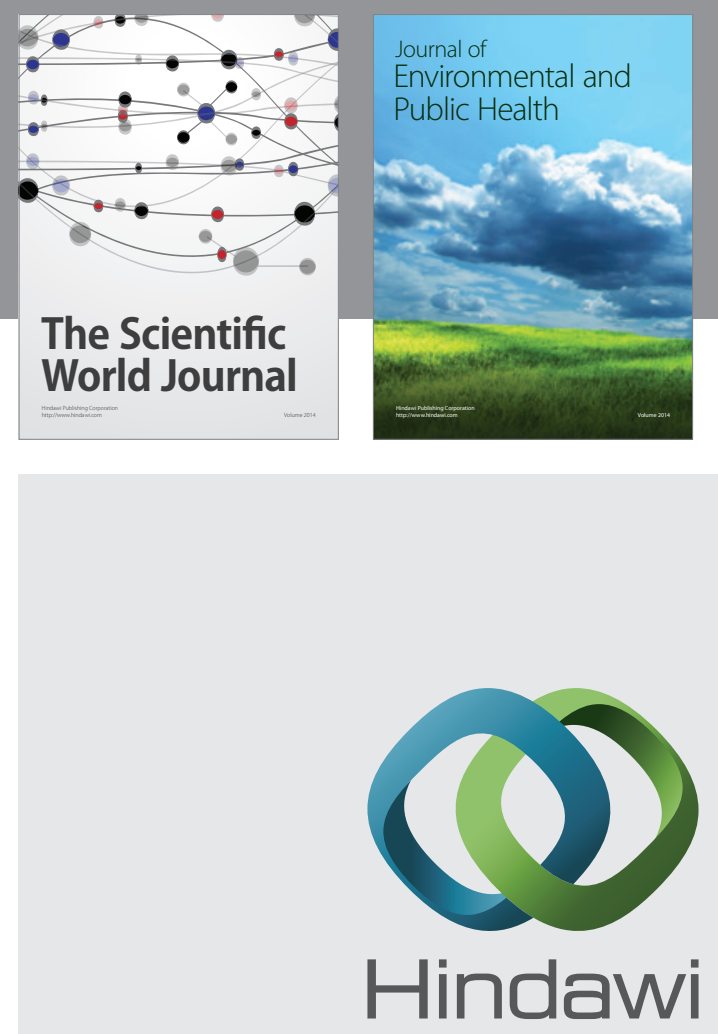

Submit your manuscripts at

http://www.hindawi.com
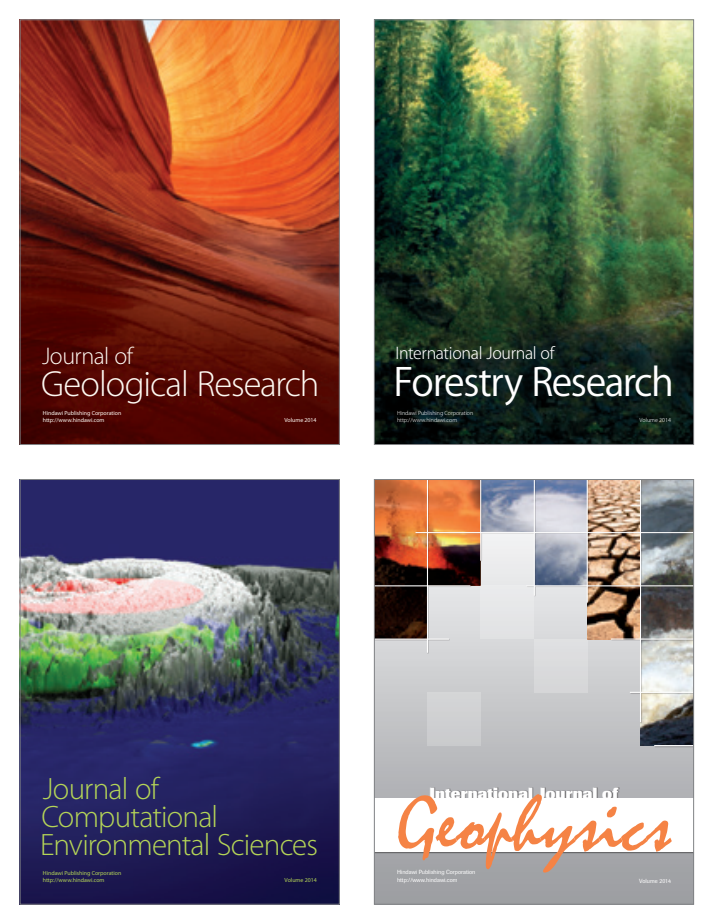
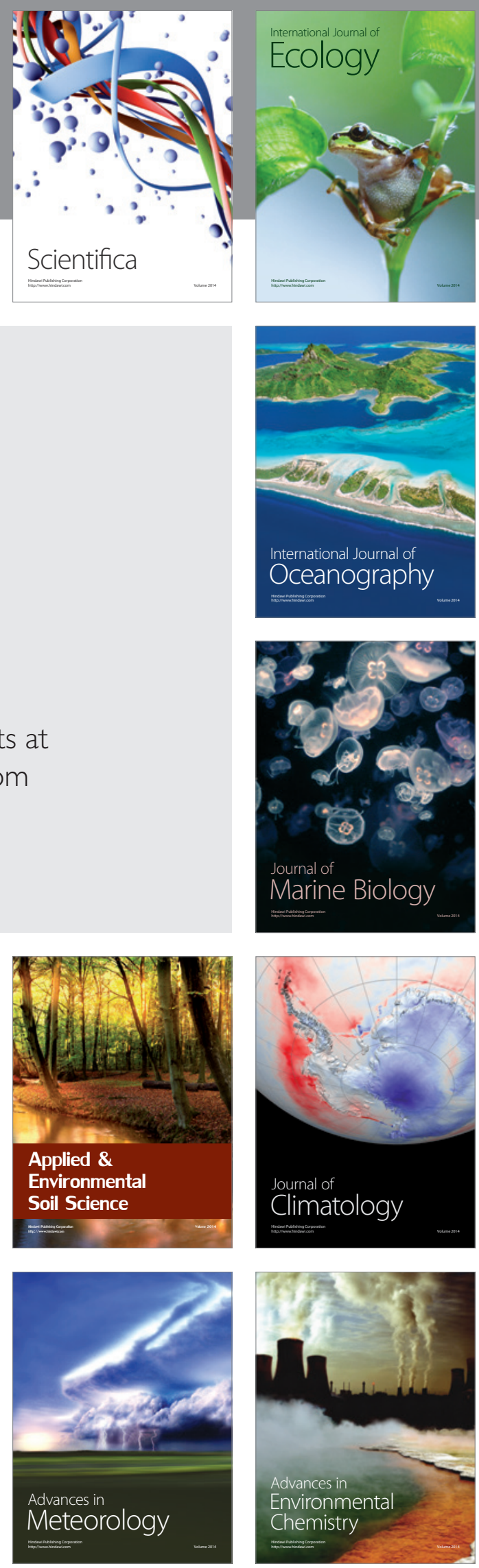